\title{
John Dunne Medal Winners
}

The 2011 and 2012 winners of the John Dunne Medal were announced recently at the College's winter 2013 Conference in Malahide, Co. Dublin.

The 2012 prize was awarded to Dr Shane McInerney for 'Burnout and its effect on Neurocognitive Performance' (co-authors Michael Rowan, Brian Lawlor) published in Irish Journal of Psychological Medicine (IJPM), September 2011. Dr McInerney is currently in Toronto doing a clinical fellowship in mood disorders, however, the award was accepted on his behalf by his mother Dr Mary McInerney (pictured at the Conference with College president Dr Anthony McCarthy).

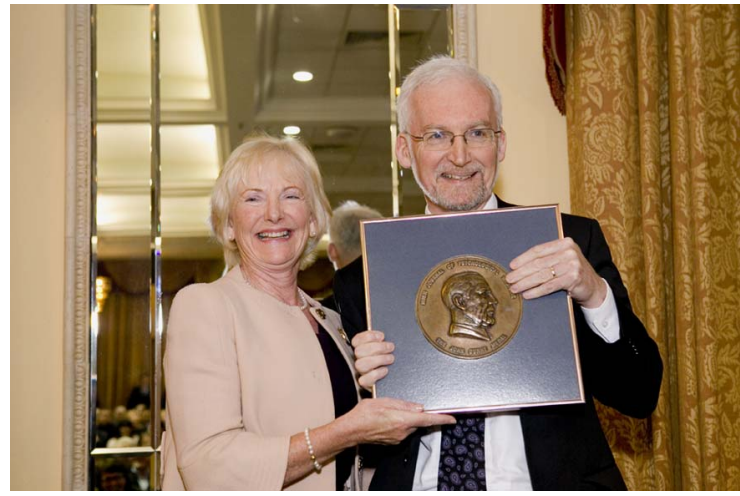

The 2011 prize was awarded to Dr Diane Mullins for 'Meeting standards set for non self-harm presentations to emergency departments' (co-authors Siobhán MacHale,
David Cotter) published in IJPM, December 2011. IJPM Editor-in-chief Professor Brendan Kelly presented the medal to Dr Mullins (also pictured).

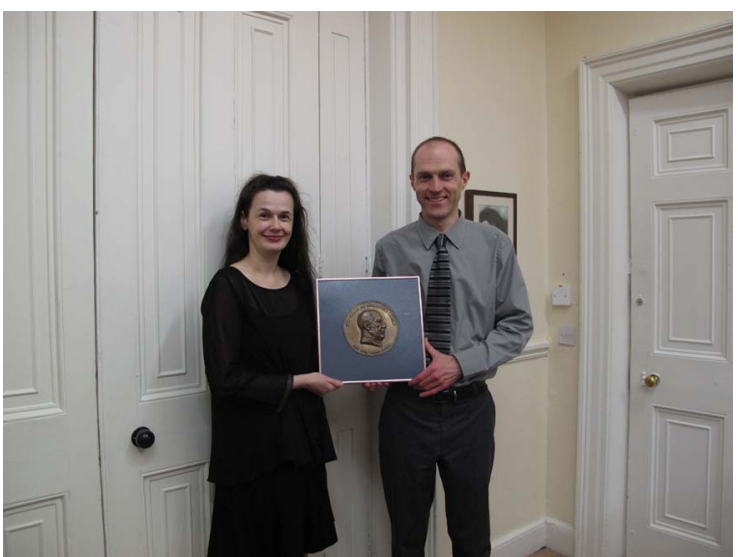

The prize was established in 1989 in honour of Dr John Dunne, first Professor of Psychiatry in Ireland and President of the Royal Medico-Psychological Association in 1955. The John Dunne Medal is now awarded annually by the Irish Journal of Psychological Medicine. The prize is open to all trainees from Ireland, Northern Ireland and Britain. To be eligible, a trainee must have made a significant contribution (though not necessarily as first author) to an original paper published by the Journal over the year. 